\title{
"Where the Social Stigma Has Been Overcome": The Politics of Professional Legitimation in Nepali Music Education
}

\author{
Danielle Shannon Treacy, Sapna Thapa, and Suyash Kumar Neupane
}

\begin{abstract}
This chapter explores the actions musician-teachers in the extremely diverse and complex context of the Kathmandu Valley imagine that might hold potential for contesting and altering processes of marginalisation and stigmatisation in Nepali society. The empirical material was generated in 16 workshops involving 53 musician-teachers and guided by the Appreciative Inquiry 4D model (e.g. Cooperrider et al. Appreciative inquiry handbook: for leaders of change. Crown Custom, Brunswick, 2005). Drawing upon the work of Arjun Appadurai, we analysed the ways in which engaging the collective imagination (1996) and fostering the capacity to aspire (2004) can support musician-teachers in finding resources for changing their terms of recognition. We identified five actions that musicians and musician-teachers take to legitimise their position in Nepali society: (1) challenging stigmatised identities, (2) engaging foreignness, (3) advocating academisation, (4) countering groupism, and (5) promoting professionalisation. We argue that these actions suggest the need for music teachers to be able to ethically and agentively navigate both the dynamic nature of culture and questions of legitimate knowledge, which may be fostered through an emphasis on professional responsibility (Solbrekke and Sugrue. Professional responsibility: new horizons of praxis. Routledge, New York, 2011) in music teacher education.
\end{abstract}

Keywords Appreciative inquiry - Capacity to aspire - Co-constructed visions · Imagination · Majority world · Music education · Nepal · Professional responsibility · Teachers' visions

\section{S. Treacy $(\bowtie)$}

Sibelius Academy, University of the Arts Helsinki, Helsinki, Finland

e-mail: danielle.treacy@uniarts.fi

S. Thapa

University of Wisconsin-Stout, Menomonie, WI, USA

e-mail: thapas@uwstout.edu

\section{S. K. Neupane}

Department of Folklore and Ethnomusicology, Indiana University Bloomington,

Bloomington, IN, USA

e-mail: sneupan@iu.edu 


\section{Introduction}

It was not until twelfth grade, when one of my music teachers invited me to teach in her grade nine band class as part of a mandatory Independent Study Unit that I discovered what I wanted to do after school. When I told my father that I had decided to apply to university to study music education, he was initially disappointed. He thought that it would be very difficult to make a decent living through music and that I would be better off pursuing engineering or the sciences. - Danielle

I grew up with academic parents who pursued music passionately. My grandmother - a selfmade businesswoman and fierce matriarch - believed in hard work and education and that music was only for people from lower castes and a waste of time that ruined families. She would call my parents 'Kami' or 'Damai' (lower caste people) and chant this 'ama maruni, bau madaley, chora chori bhaldang bhuldung - dey na latta ley' meaning 'parents who spend time playing or performing music and not looking after their children should be kicked'. - Sapna

Waiting to receive the Nepal Scholar Award from the President of Nepal, I overheard a fellow graduate say it was 'unfair' that a music graduate had won the Vice Chancellor Gold Medal, when somebody studying a more 'difficult' subject actually deserved it. Such experiences have often made me question the status of music students and musicians. People have a dismissive attitude towards those who study or play music - a subject they still consider unworthy of serious academic interest in Nepali society today. - Suyash

Despite the importance of music in daily life in Nepal - not only permeating social life and festivities but often expected or mandatory for various occasions - musicians have generally been positioned in a stigmatised position at the bottom of the social hierarchy (e.g. Tingey 1995). It is perhaps not surprising then that during a series of workshops focused on co-constructing visions for Nepali music education, musician-teachers aspired To live in a society where music is valued, including where people recognise that music is vital, where the social stigma has been overcome and where music is for all. Indeed, a desire for legitimation pervaded the workshop discussions and resulting visions (see Table 9.1), as the musicianteachers envisioned not only music and music education but themselves as musicians and music teachers and their choice to be musicians and music teachers, as legitimate and valuable. The musician-teachers, however, did not merely envision their desired societal changes. They also envisioned actions for achieving these changes. As stories of musics and musicians being devalued, discriminated against, or stigmatised can be found both inside and outside of Nepal, the actions envisioned by the musician-teachers not only have direct implications in Nepal but also suggest some of the challenges and ethical dilemmas music teachers and music teacher educators may face globally while negotiating a world of intensifying diversity and uncertainty.

In this chapter, we explore how the politics of legitimation intersect with music education and schooling, in a context characterised by extremely diverse musics, ${ }^{1}$

\footnotetext{
${ }^{1}$ We use the words "musics", "cultures", and "traditions" acknowledging the existence of their multiplicity and diversity in Nepal.
} 
Table 9.1 Summary of the co-constructed visions (organised by order of reference in the chapter; see also Treacy 2020b)

To live in a society where music is valued, including where people recognise that music is vital, where the social stigma has been overcome and where music is for all

To develop an internationally recognised music and music education (music teacher training) course in Nepal through affiliations with an outside university for Nepali, eastern, and western musics

That music would be an included (and valued) subject in schools

To have properly designed music organisations with enough instruments, proper classes, etc.

To develop unity between the major music institutions in Nepal so that activities become more controlled and efficient

To create a music community that brings all music lovers to work together and create professionalism

That music teachers would use a variety of teaching and learning techniques in the classroom to make learning easier for students because no one method will work for every teacher or every student

ways of being and becoming a musician, and forces imposing stigma. Thinking with sociocultural anthropologist Arjun Appadurai, we examine how engaging the collective imagination (1996) and capacity to aspire (2004) supports musician-teachers in finding resources for changing their "terms of recognition" (Appadurai 2004, p. 66). After contextualising the stigmatised position of musician-teachers in Nepal and describing our mode of inquiry, the chapter presents five actions musicianteachers imagined that might hold potential for contesting and altering processes of marginalisation and stigmatisation in Nepali society. We then reflexively interpret these actions in relation to professional responsibility (Solbrekke and Sugrue 2011).

\section{Music and Stigma in Nepal}

Nepal is characterised by extreme and highly complex diversity, and a long history of social stratification, wherein caste/ethnicity has long ascribed social status and profession. Although currently recognising 126 caste/ethnic groups, 123 languages spoken as mother tongue, and 10 religions (Government of Nepal 2012, p. 4), these categories are not separate and fixed but overlapping and in constant flux as identities are formed and reclassified, by both state and people, as groups work to "renegotiate their identities and their place in the state" (Hangen 2010, p. 28).

Since Nepal's founding in 1769, the caste hill Hindu elite have dominated cultural and socio-political life, while marginalised castes/ethnicities, including indigenous nationalities, Madhesis, and Dalits, have faced linguistic, religious, ethnic, sociocultural and geographical discrimination, and unequal access to state and societal resources (Lawoti 2012). This discrimination was formalised and legally enforced in the 1854 Muluki Ain (Law of the Land), a five-tiered caste hierarchy, based on the Hindu philosophical division of labour and relative purity (Hangen 2010). The 1962 
constitution constructed "a deceptive façade of peace and ethnic harmony" through tight state control, official historical narratives, education, and the media (Lawoti 2012, p. 129), and although the 1990 constitution declared multi-ethnicity, secularism, and democracy, persisting inequality and discrimination fuelled a decade-long civil war (1996-2006). The post-2006 peace process saw inclusion become widespread rhetoric; however, this rhetoric has yet to manifest in areas of consequence hence informal discrimination persists (Lawoti 2012).

In the Muluki Ain, musician castes were positioned in the lowest two tiers, with some musician castes such as the Kusle and Kulu classified as touchable, and others, such as the Badi, Damai, and Gaine as untouchable (Subedi 2010), meaning contact with them required ritual purification (Tingey 1995). A disparity exists, however, between caste musicians' stigmatised position and the auspiciousness and indispensable nature of the musics, instruments, and musicians themselves (Tingey 1992, 1995), which are even considered "essential for the well-being" of society (Tingey 1992, p. 97). Besides stratifying society, the caste system also prevented cultural, including musical, exchange between caste/ethnic groups (Moisala 2013). While caste-related stigma and restrictions do not apply to those playing western instruments (Tingey 1995), these musicians are also affected by hierarchy and negative stereotypes, with female musicians in particular experiencing marginalisation (e.g. Treacy 2020a).

Despite the perceived stigma, music education is currently offered in music institutes and as extracurricular or curricular studies in some private schools. Music is included in the primary school national curriculum under Social Studies' "Creative and Performance Art". In addition, music curricula for grades 1-5 (ages 6-11) have been developed by the Nepal Music Center and approved by the Ministry of Education as a local subject, meaning schools can develop their own curricula. For grades 6-8 (ages 12-14) music is included as the second of two possible optional subjects wherein the school selects the subject from a group of possible subjects which is then taken by all students. For grades 9-12 (ages 15-18), music is implemented under the technical and vocational stream. At the tertiary level, it is possible to study music and dance at Tribhuvan University and ethnomusicology at Kathmandu University (see also Treacy 2020c).

\section{Mode of Inquiry}

The empirical material for this chapter was generated as part of a larger research project through a series of 16 workshops involving 53 musician-teachers working in the Kathmandu Valley. These workshops were co-facilitated by the first author in three groups. Group A had eight 3-hour workshops, the first two of which were repeated on 2 separate days in an attempt to widen participation; group B had four 2-hour workshops; and Group C had two workshops from 1.5-2 hours each with the intention of Group C participants later joining Group B. The workshops were guided by the Appreciative Inquiry 4D model (e.g. Cooperrider et al. 2005) and resulted in seven co-constructed visions (see Table 9.1). The workshops have been described in 
detail elsewhere (see Treacy 2020b) as has the methodology of the larger research project (see Treacy 2020c).

The empirical material was analysed and reflexively interpreted (Alvesson and Sköldberg 2009) in relation to professional responsibility (Solbrekke and Sugrue 2011). The process of cross-cultural co-authoring was particularly influential. The authors are Danielle Treacy, a Canadian-born music educator and researcher currently living in Finland; Sapna Thapa, a Nepali member of the larger research project's international advisory board and associate professor in the USA; and Suyash Kumar Neupane, a Nepali workshop participant and graduate student of ethnomusicology in the USA. Our preliminary exploration of global influences in Nepali music education, an issue highlighted during the workshops, drew our attention to the local, while reflexive interpretation against the larger research project (see Treacy 2020c), the complex context of Nepal, and the co-authors' lived experiences underscored the desire for professional legitimation as a theme cutting across the co-constructed visions. Aiming at "inquiry as productive critique" (Kuntz 2015, p. 109) of stratification in society, we followed a process of abduction (Alvesson and Sköldberg 2009). Alternating between the empirical material, theory, and discussions, we identified five actions discussed by the musician-teachers related to contesting marginalisation and overcoming stigma. This involved relistening to and re-analysing the approximately 40 hours of workshop discussions, supported by individual and group written responses, and regularly reinterpreting the analysis with all co-authors. All direct quotations are of workshop participants and in their original English. As the focus of the workshops was on co-constructing knowledge, individuals are not identified.

\section{Legitimating Actions}

Our analysis identified five actions described by the participating musician-teachers as "locally plausible ways" (Appadurai 2004, p. 66) of contesting and altering their marginalised position in society. These actions towards professional legitimation were: (1) challenging stigmatised identities, (2) engaging foreignness, (3) advocating academisation, (4) countering groupism, and (5) promoting professionalisation.

\subsection{Challenging Stigmatised Identities}

While workshop participants were musicians by choice, they spoke of the challenges faced by "cultural musicians", those "who are doing the ritual duties, who are assigned by the society as musician, who have their grandfathers, forefathers... passing on the legacy to their children." Because of the desire for "freedom" and to be "socially accepted by other castes", the participants described how cultural musicians have been changing their surnames to names related to higher castes (see also Moisala 2013). This means, however, also abandoning their instruments 
because "if he is no longer Damai... he can no longer play damaha". The participants generally perceived cultural musicians to be "struggling... fighting ... for their identity" and Nepali musics to be "suffering" and "in crisis". It was even asserted that "We don't know what Nepali music is". The music performed by some groups, however, such as the Damai's panchai baja - a very auspicious ensemble compulsory for festivals and weddings - is so important that a story was shared of one village, where, after the Damai abandoned their instruments, "other castes took the initiative and they started playing the instruments, and they popularised them". Still, this raised a concern that "The instrument goes on but it loses its main essence because the context is completely different". Thus, while the stigma associated with being a cultural musician causes musicians to abandon their names and instruments, individuals, institutions, and local initiatives such as Project Sarangi are becoming concerned with the preservation of some musics perceived to be undervalued or at risk of vanishing due to their association with lower castes.

Accordingly, the musician-teachers envisioned music education in schools to play a crucial role in countering the crisis of the loss of Nepali cultural musicians and their musics and addressing the challenges they encounter. Much resistance was anticipated, however, as parents do not want their children to play low caste instruments or even bring them into their homes. Even Kathmandu University ethnomusicology students among the workshop participants had been questioned or scolded for playing certain instruments in their home or visiting certain communities or musicians to research their musics. This stigma, however, was perceived to be changing as some people from higher castes begin to show interest in lower caste instruments. Still, there was a perceived need for a movement towards greater acceptance of folk musics and instruments "regardless of social stigma", to "respect all forms of music players, not only the pop stars or rock stars, but also the panchai baja players". One musician-teacher elaborated:

If there is respect for individual thought, then I think it will be good for the people who want to do music, or any other thing that is not what society wants.... If he is in a higher class but he wants to do something that is in a lower class, because it is his individual choice, he should be encouraged.

\subsection{Engaging Foreignness}

The musician-teachers described various ways foreign influences served social distinction. As music is not widely taught in government schools, it continues to be a subject usually taught by private teachers or at music institutes and private schools. Therefore, music education remains a privilege for those who can afford the related fees, and parents still often prefer their children to learn foreign instruments.

\footnotetext{
${ }^{2}$ Damaha is a bowl-shaped drum, played with a pair of sticks. It is usually identified with the Damai people.
} 
Indeed, performing foreign musics was compared to "speak[ing] English properly" and occupying a "very heightened space". Lessons in instruments like the piano, for example, were associated with wealth and jealousy or competition between families. Consequently, some families not only encourage their children to learn musics associated with higher status but sometimes with "pushing, forcing", even if "the student... doesn't want to play anything". When one private school hired a famous Nepali folk ensemble to teach music as an extracurricular subject, they were teaching the cajon, not madal, ${ }^{3}$ and guitar, not sarangi. ${ }^{4}$ It was even suggested that students in private schools, where the primary language of instruction is English, feel embarrassed to learn Nepali musics. One musician-teacher explained, "In Kathmandu we are brought up in a rather western influenced environment. All of us want to play bass guitar and drums and guitars rather than our own instruments". Thus, it was lamented:

our music is dying, literally. It will die in two, three decades, and all of us will be in jazz combos, and funk music, and punk music, and rock and roll music.... Even the people who don't mind...being associated with the lower caste, we're just not into that music, I don't know why. It's us who are supposed to give a new direction to that music, to those instruments.

Others noted, however, that playing a foreign instrument had been their route to learning about or performing Nepali musics.

While foreign influences were described as pulling attention outwards, they were also seen to give power to local instruments and musics. Foreigners' appreciation for and interest in learning Nepali instruments like the sarangi were seen to elevate the instruments from something of untouchables to something people of higher castes were now willing and interested in learning. Even the desire to preserve Nepali musics was connected to them being valued by foreigners:

foreign people came to Nepal, and Nepalese people understood that Nepali music is something that [foreigners are] interested in. That's when the clever people wanted to preserve this thing.

Thus, the increasing interest in world music - defined by Schippers (2010) as musics that travel and interact with new contexts (p. 28) - draws international attention and enthusiasm to local Nepali musics.

The power associated with the foreign was also intimately connected to a desire for international comparability and mobility, seen in the vision, to develop an internationally recognised music and music education course in Nepal through affiliations with an outside university. Indeed, some of Nepal's music education institutions were established with foreign support, and some musicians choose to participate in foreign exams offered, for example, by institutions such as ABRASM or Rock School for western musics or by Kalanidhi Indira Sangeet Mahavidhyalaya -

\footnotetext{
${ }^{3}$ Madal is a cylindrical double-headed membranophone played with two hands and common in various Nepali folk music genres.

${ }^{4}$ Sarangi is a bowed chordophone played upright and associated with the untouchable Gandharva/ Gaine ethnicity.
} 
accredited by Indian institutions - for eastern classical music. Furthermore, as part of the Global Visions project, ${ }^{5}$ four Nepal Music Center teachers completed pedagogical studies according to Finnish requirements with context-specific content.

\subsection{Advocating Academisation}

The musician-teachers recognised the important role of institutions in repositioning music in both schooling and society. Included in the co-constructed visions was that music would be included as a valued subject in schools and to have properly designed music organisations with enough instruments and proper classes. Valuing music in schools was often linked to music learning being structured, through syllabi, lesson plans, and assessments. Indeed, including music as a core school subject was described as "the first thing we can do right now" to legitimate music. Since the School Leaving Certificate (SLC) examinations frame curricular choices, subjects and extracurricular activities not examined in the SLC are often discontinued in grades 9 and 10 (see e.g. Treacy, Timonen, Kallio and Shah 2019). If music were to be included, however, "parents will have in their mind that the exam is coming so [their children] will [be able] to practice". Moreover, "Having music education in the schools itself is a big thing because it provides opportunities for the teachers as well as the students", as schools "contribute by hiring us as teachers" and "provide a good salary for musicians to survive". Academisation was also important for preservation, and some private schools explicitly try to promote Nepali folk musics. The musician-teachers explained "We have to preserve our tradition" and "We have to create our own uniqueness, not following randomly the foreign traditions". Care was required, however, because "if you force that because it is our tradition, our culture, then... it's not gonna work" as students "will lose interest". Importantly, not only learning to perform Nepali musics was deemed necessary for preservation but also how to make Nepali instruments.

There was criticism, however, towards the perceived lack of value of music in schools. Music teachers were said to be hired only to teach songs as the schools "just want the kids to perform" not "grow in a musical direction...because that takes time". In particular, many schools "just want [music] teachers for Parents Day", where music is seen as a kind of publicity for the school. Some schools even hire teachers just to prepare a performance, firing them soon after. Another criticism was that music as an extracurricular activity was "just [to] earn more money from the parents" through "extra fees". Accordingly, the musician-teachers frequently discussed the need for what they called "music awareness", posing questions such as "Why are

\footnotetext{
${ }^{5}$ The Global Visions through Mobilizing Networks: Co-developing Intercultural Music Teacher Education in Nepal, Finland, and Israel (https://sites.uniarts.fi/web/globalvisions) is the larger research project to which this chapter contributes.
} 
there music lessons in the school?" and "Why do you want your students or your children to learn music in school?"

\subsection{Countering Groupism}

Discrimination was identified as not only coming from non-musicians in Nepali society. The musician-teachers identified "groupism" - a kind of discrimination depending on "what kind of musical circle you are in"- as an area of concern. The musician-teachers, for example, explained how music students differentiate themselves depending on whether they play western or eastern instruments and do not want to engage with students of other kinds of music, each group thinking that they are superior to the other. In addition, the musician-teachers discussed how "there is a lot of distance between" different music institutes in the Kathmandu Valley. Consequently, to encourage mobility between institutions and musical cultures, one of the visions was to develop unity between the major music institutions in Nepal. Additionally, "getting to know others from different backgrounds" and "appreciating and learning through difference" were seen to be important, as was learning "music from another culture or ethnicity". Overall, musicians' regard for each other was viewed as crucial:

Unless music teachers, music learners, and music researchers view one another with equal respect, we cannot expect society to view music positively as a whole and community building isn't possible.

Groupism appeared to be connected to a larger societal issue. While participants expressed that "The most important thing is building a community of music teachers to work together to improve the quality of music education", they added that "even if a community is formed, there will be fractures or factions based on nepotism, favouritism, difference in customs or ethnicity, or religion, or groupism". This was described as something that "prevails in our society", "how it has always been", and due to "the ill effects of politics and its infection on professionalism and community". Hence, it was perceived as an issue of equality that provoked the need to:

provide equal opportunities to all music professionals regarding ethnicity, regarding their caste, regarding their colour, regarding their physical disabilities. We should not create any barriers. We should have to provide equal opportunities for their growth and development.

\subsection{Promoting Professionalisation}

Professionalisation was seen to be required for careers in music to be regarded as legitimate. Participants expressed that being "a musician is not regarded as a real profession" but a pathway to joblessness. Indeed, "the social image of musicians [is] useless"- even "in the dustbin"- and music is "just for passing your time, for 
entertainment". Workshop discussions addressed the lack of support from parents, both emotional and financial, and the awkwardness supportive parents experienced when explaining that their child was a musician or studying music, sometimes even hiding it. A musician-teacher recalled, "my father didn't tell even my relatives that I was studying music ... until I received my diploma.... Even parents they support you, but that's a secret support". Thus, convincing parents and grandparents - their own and their students' - that music was worth pursuing was felt as both a need and challenge.

Since "most parents think their children are successful when they earn money" there was also a "need to make [society] aware that [music] can be a career". Thus, the musician-teachers envisioned being "the practical example that anyone who is in music can have a secure future .... And is socially active". Indeed, many musicianteachers held a sense of social responsibility, for example, a small group volunteered to co-teach music lessons in a private school in exchange for free tuition for underprivileged children. Contrary to the beliefs commonly held in society, musician-teachers suggested that studying music helped in potentially "dealing with [the high] unemployment" rate in Nepal, because "safe career path[s]" like "engineering and science ... and medicine... don't have jobs because there are too many [people qualified in these fields]. And musicians, at least they can play and earn some money" or work as music teachers. However, an unseen hierarchy regarding teachers of various subjects and discrimination in salaries were described as challenges to being equally valued.

In addition to securing employment, professionalisation was also associated with being trained or qualified, with particular importance placed on recognised certificate courses. This was particularly important in the absence of government-recognised music teacher education, which caused challenges for participants in proving their skills when applying for jobs. One piano teacher stressed the importance of his ethnomusicology degree from Kathmandu University, despite not receiving any piano lessons as part of the degree, and another described how "the principal just asked me one question, do you know how to read notation?... She didn't even ask me what you are going to teach with that notation?" Certification was also necessary to "apply for a university outside, and get a scholarship". However, it was also suggested that "not all music teachers should have that academic qualification" because "in eastern and folk music we don't have that system of certification". Instead:

if you learn dhimey... ${ }^{6}$ people know you're qualified... after the function called Pirane Puja... when the music student comes out to the public and plays .... So, that's how the whole society says okay, now he is qualified ...that's his certificate.... So we need to consider them based on their experiences.

Finally, sustaining a network of music teachers was also seen as a means to professionalisation, as in the vision, To create a music community that brings all music lovers to work together and create professionalism.

\footnotetext{
${ }^{6}$ Dhimey is a double-headed cylindrical membranophone played by Newar communities during festivals and rituals. It is played with the combination of a thin stick and hand on each side.
} 


\section{Towards Professional Responsibility}

The five actions above make clear that music education is not neutral but entangled with various historical, political, economic, and sociocultural complexities. By highlighting tensions musician-teachers must negotiate, both as individuals and as an emerging profession in Nepal, the actions also suggest that conceptualisations of professionalism in music education require a move beyond expertise to considerations of professional responsibility, encompassing wider conceptions of social service and ethical standards (Solbrekke and Sugrue 2011). In particular, the tensions in these actions suggest that professional responsibility in music education requires, among other things, a capacity to ethically and agentively navigate both the dynamic nature of culture and questions of legitimate knowledge.

The actions of challenging stigmatised identities and engaging foreignness remind us that culture is not static, but "a dialogue between aspirations and sedimented traditions" (Appadurai 2004, p. 84) and "an arena for conscious choice, justification, and representation" (Appadurai 1996, p. 44). This challenges national objectives for education, like "prepar[ing] citizens committed to conserve and promote Nepali art, aesthetic values, ideals and other specialties" (Government of Nepal 2007, p. 32), as workshop discussions indicated both an uncertainty regarding what "Nepali music" is and a need to find a unique Nepali musical identity. In an extremely diverse, post-conflict country, where each of the over 120 caste/ethnic groups has unique musical cultures, whose musics are conserved and promoted as Nepali? Moreover, considering the historical association of outside influences in Nepal with both constructing social distinction and "dangerous defilement" (Liechty 1997, p. 23), what Nepali musics have been and what they may become are shaped not only by the past and local but also by the future and global. In aspiring to a more equitable future, therefore, professional responsibility could also encompass the sense of agency, even activism, demonstrated by the workshop participants in countering societal resistance - by raising awareness and respect for individual choice - and dismantling societal and musical boundaries and hierarchies. However, as recognised by the participants "changing the attitude of society" is "a very long process".

It is not only individual music teachers and the music teaching profession who are required to contend with such dilemmas. The actions advocating academisation and promoting professionalisation remind us of the legitimating function of academic institutions. Indeed, the musician-teachers envisioned music as legitimate knowledge (Apple 2004), legitimating music not only as a subject of study but also as a career more broadly. Consequently, as music enters schools, professional responsibility also involves ongoing critical reflection on this legitimating function, as "schools confer cultural legitimacy on the knowledge of specific groups" (Apple 2004, p. 61, our italics) rather than all groups. Thus, intense debates about which musics should be studied, researched, and performed in academic institutions, such as those that took place in the workshops, are profoundly complicated and ethical debates. This demands that institutions examine their visions for music education and their role in reproducing and dismantling hierarchies, as - contrary to the place of schooling in 
the public imagination as enabling social mobility - education has long been "the primary sorting mechanism in society" (Patel 2016, p. 30). An explicit vision to promote Nepali folk musics was held by some of the schools in this study. Such a vision enables musics that have traditionally held lower status to enter schools. This musical gentrification (Dyndahl et al. 2014), however, not only changes lower status musics into something to be acquired by people of higher status and power. Educational contexts also reshape the musics (Dyndahl et al. 2014). Thus, professional responsibility ought to include constantly asking, and re-asking, what musics are included, what musics are excluded, why and with what consequences, and how might different musics need to be reshaped, so that systems of inequity are not maintained.

\section{Concluding Thoughts}

In this chapter, we explored the politics of legitimation in music education in an extremely diverse society. In particular, we focused on actions described by musician-teachers in the Kathmandu Valley for legitimating music (in general and the vast diversity of musics in Nepal), music education, and both being and becoming a musician or music teacher. The chapter emphasises the important role of music educators' imaginations and aspirations in articulating and countering discrimination through envisioning actions that may contribute to a more transformative and socially just music education and society more broadly. The case of musicianteachers in the Kathmandu Valley, therefore, reminds us of the need to critically re-examine our own contexts. Thus, we suggest that it is imperative for music teacher education globally to nurture future teachers' capacities to aspire and to envision not only their ideal future classrooms or what good teaching could be but also the place of their teaching and subject in shaping more just future societies. To this end, music teacher education could be developed to include critical reflection on societal structures and power issues shaping the field and provide space for teachers to not only imagine how those structures may be dismantled (Patel 2016, p. 74) but to allow their imaginations to become the "fuel for action" (Appadurai 2004, p. 7). In doing so, professionally responsible music teachers and music teacher educators could work towards the social changes required to meet global calls for more inclusive societies, such as the Nepali objectives for education which aspire to counter hegemonic constructs like untouchability and "develop a strong sense of non-discrimination towards others despite their caste, ethnicity, religion, language, gender, class, and disability" (Government of Nepal 2007, p. 41).

Acknowledgements The authors would like to thank the musician-teachers who participated in the workshops and shared their perspectives and experiences as part of this research, dhanyabaad! We would also like to thank Iman Shah, principal of the Nepal Music Center, for his assistance verifying the current state of music education in Nepal, and the doctoral community at the Sibelius Academy of the University of the Arts Helsinki for comments and guidance in refining this text. 
Open Access An earlier draft of this chapter was originally published in Treacy's (2020) Imagining Possibilities: Musician-Teachers Co-constructing Visions in the Kathmandu Valley (Sibelius Academy of the University of the Arts Helsinki, Studia Musica 80, http://urn.fi/URN:NBN:fife202002145503). The earlier draft was licensed under the terms of the Creative Commons Attribution 4.0 International License (http://creativecommons.org/licenses/by/4.0/). Very minor changes have been made to the Abstract and Mode of Inquiry in this version, and the reference list has been updated.

Funding This research has been undertaken as part of the project Global Visions through Mobilizing Networks: Co-developing Intercultural Music Teacher Education in Nepal, Finland, and Israel funded by the Academy of Finland (2015-2020, project no. 286162).

\section{References}

Alvesson, M., \& Sköldberg, K. (2009). Reflexive methodology: New vistas for qualitative research (2nd ed.). Los Angeles: SAGE.

Appadurai, A. (1996). Modernity at large: Cultural dimensions of globalization. Minneapolis: University of Minnesota Press.

Appadurai, A. (2004). The capacity to aspire: Culture and the terms of recognition. In V. Rao \& M. Walton (Eds.), Culture and public action (pp. 59-84). Stanford: Stanford University Press. Apple, M. (2004). Ideology and curriculum (3rd ed.). New York: RoutledgeFalmer.

Cooperrider, D. L., Whitney, D., \& Stavros, J. M. (2005). Appreciative inquiry handbook: For leaders of change (2nd ed.). Brunswick: Crown Custom.

Dyndahl, P., Karlsen, S., Skårberg, O., \& Nielsen, S. G. (2014). Cultural omnivorousness and musical gentrification: An outline of a sociological framework and its applications for music education research. Action, Criticism, and Theory for Music Education, 13(1), 40-69.

Government of Nepal. (2007). National curriculum framework for school education in Nepal. Bhaktapur, Nepal. Retrieved from http://www.moe.gov.np/assets/uploads/files/National-Curric ulum-Framework-2007-English.pdf https://www.moe.gov.np/assets/uploads/files/National-Cur riculum-Framework-2007-English.pdf

Government of Nepal. (2012). National population and housing census 2011 (National report). Retrieved from http://unstats.un.org/unsd/demographic/sources/census/wphc/Nepal/Nepal-Cen sus-2011-Vol1.pdf

Hangen, S. I. (2010). The rise of ethnic politics in Nepal: Democracy in the margins (special Nepal ed.). London: Routledge.

Kuntz, A. M. (2015). The responsible methodologist: Inquiry, truth-telling, and social justice. London: Routledge.

Lawoti, M. (2012). Ethnic politics and the building of an inclusive state. In S. von Einsiedel, D. M. Malone, \& S. Pradhan (Eds.), Nepal in transition: From people's war to fragile peace (pp. 129-152). New Delhi: Cambridge.

Liechty, M. (1997). Selective exclusion: Foreigners, foreign goods, and foreignness in modern Nepali history. Studies in Nepali History and Society, 2(1), 5-68.

Moisala, P. (2013). "Nobody should be forced to make a living by begging": Social exclusion and cultural rights of Gaine/Gandharva musicians of Nepal. Yearbook for Traditional Music, 45, 13-27.

Patel, L. (2016). Decolonizing educational research: From ownership to answerability. New York: Routledge.

Schippers, H. (2010). Facing the music: Shaping music education from a global perspective. Oxford: Oxford University Press.

Solbrekke, T. D., \& Sugrue, C. (2011). Professional responsibility - Back to the future. In C. Sugrue \& T. D. Solbrekke (Eds.), Professional responsibility: New horizons of praxis (pp. 12-28). New York: Routledge. 
Subedi, M. (2010). Caste system: Theories and practices in Nepal. Himalayan Journal of Sociology \& Anthropology, IV, 134-159. Retrieved from https://www.nepjol.info/index.php/HJSA/article/ viewFile/4672/3886

Tingey, C. (1992). Sacred kettledrums in the temples of Central Nepal. Asian Music, 23(2), 97-103. https://doi.org/10.2307/834175.

Tingey, C. (1995). The Pancai Baja: Reflections of social change in traditional Nepalese Music [digital image]. Retrieved from http://www.dspace.cam.ac.uk/handle/1810/227167

Treacy, D. S. (2020a). "Because I'm a girl": Troubling shared visions for music education. Research Studies in Music Education, 42(3), 310-325. https://doi.org/10.1177/ $1321103 X 19845145$.

Treacy, D. S. (2020b). Engaging practitioners as inquirers: Co-constructing visions for music teacher education in Nepal. In H. Westerlund, S. Karlsen, \& H. Partti (Eds.), Visions for intercultural music teacher education (Landscapes: The arts, aesthetics, and education) (Vol. 26, pp. 195-294). Springer. https://doi.org/10.1007/978-3-030-21029-8_13.

Treacy, D. S. (2020c). Imagining possibilities: Musician-teachers co-constructing visions in the Kathmandu Valley. Sibelius Academy of the University of the Arts Helsinki. Studia Musica 80. http://urn.fi/URN:NBN:fi-fe202002145503

Treacy, D. S., Timonen, V., Kallio, A. A., \& Shah, I. B. (2019). Imagining ends-not-yet-in-view: The ethics of assessment as valuation in Nepali music education. In D. J. Elliott, M. Silverman, \& G. E. McPherson (Eds.), The Oxford handbook of philosophical and qualitative assessment in music education (pp. 411-429). New York: Oxford University Press. https://doi.org/10.1093/ oxfordhb/9780190265182.013.33.

Danielle Shannon Treacy is a lecturer at the Sibelius Academy of the University of the Arts Helsinki, Finland. Her interdisciplinary research focuses on the ethical and methodological deliberations involved in intercultural music teacher education policy, practice, and research, and collaborative learning and reflective practice in higher arts education. At the university level, she currently teaches in the MuTri Doctoral School and the Global Music Department.

Sapna Thapa is an Associate Professor of Early Childhood Teacher Education in the University of Wisconsin-Stout. Her research interests are cultural teaching practices, diversity, and equity in early childhood education. Her recent research project is a cross-cultural collaborative study that explores emotional experiences of preservice teachers.

Suyash Kumar Neupane is currently pursuing doctoral studies in Ethnomusicology at the Department of Folklore and Ethnomusicology, Indiana University Bloomington, USA. His research interests include structural casteism in the musics of Nepal, collaborative ethnographic approaches to the recontextualisation of archival and museum collections of South Asian musics, and multisensorial ethnography pertaining to the relationship between food and sound.

Open Access This chapter is licensed under the terms of the Creative Commons Attribution 4.0 International License (http://creativecommons.org/licenses/by/4.0/), which permits use, sharing, adaptation, distribution and reproduction in any medium or format, as long as you give appropriate credit to the original author(s) and the source, provide a link to the Creative Commons license and indicate if changes were made.

The images or other third party material in this chapter are included in the chapter's Creative Commons license, unless indicated otherwise in a credit line to the material. If material is not included in the chapter's Creative Commons license and your intended use is not permitted by statutory regulation or exceeds the permitted use, you will need to obtain permission directly from the copyright holder.

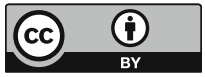

